\title{
UNIVERSITYOF
}

FORWARD

THINKING

WESTMINSTER用

WestminsterResearch

http://www.westminster.ac.uk/westminsterresearch

Values in middle childhood: Social and genetic contributions

Döring, A.K., Uzefovsky, F. and Knafo-Noam, A.

This is the accepted version of the following article: Döring, A.K., Uzefovsky, F. and Knafo-Noam, A. (2015) Values in middle childhood: Social and genetic contributions Social Development DOI: 10.1111/sode.12155, which has been published in final form at https://dx.doi.org/10.1111/sode.12155

The WestminsterResearch online digital archive at the University of Westminster aims to make the research output of the University available to a wider audience. Copyright and Moral Rights remain with the authors and/or copyright owners.

Whilst further distribution of specific materials from within this archive is forbidden, you may freely distribute the URL of WestminsterResearch: ((http://westminsterresearch.wmin.ac.uk/)).

In case of abuse or copyright appearing without permission e-mail repository@westminster.ac.uk 
Running head: SOCIAL AND GENETIC CONTRIBUTIONS TO CHILDREN'S VALUES

Values in Middle Childhood: Social and Genetic Contributions

Florina Uzefovsky ${ }^{1,2}$, Anna K. Döring ${ }^{3}$, \& Ariel Knafo-Noam ${ }^{1}$

${ }^{1}$ The Hebrew University, Jerusalem, Israel

${ }^{2}$ University of Cambridge, UK

${ }^{3}$ Royal Holloway, University of London, UK 


\begin{abstract}
Theories of value development often identify adolescence as the period for value formation, and cultural and familial factors as the sources for value priorities. However, recent research suggests that value priorities can be observed as early as in middle childhood, and several studies, including one on preadolescents (Knafo \& Spinath, 2011), have suggested a genetic contribution to individual differences in values. In the current study, 174 pairs of monozygotic and dizygotic 7-year old Israeli twins completed the Picture-Based Value Survey for Children (PBVS-C; Döring et al., 2010). We replicated basic patterns of relations between value priorities and variables of socialisation - gender, religiosity, and socioeconomic status- that have been found in studies with adults. Most important, values of Self-transcendence, Self-enhancement, and Conservation, were found to be significantly affected by genetic factors $(29 \%, 47 \%$ and $31 \%$ respectively), as well as non-shared environment (71\%, 53\% and $69 \%$ respectively). Openness to change values, in contrast, were found to be unaffected by genetic factors at this age and were influenced by shared (19\%) and non-shared $(81 \%)$ environment. These findings support the recent view that values are formed at earlier ages than had been assumed previously, and they further our understanding of the genetic and environmental factors involved in value formation at young ages.
\end{abstract}

Keywords: children's values, value priorities, genetics, twin study, gender, religiosity, socioeconomic status 


\section{Values in Middle Childhood: Social and Genetic Contributions}

Values, the abstract goals used to guide behaviors and to evaluate actions, persons, and the self (Schwartz, 1992), are a core component of culture (Hofstede, 2001). The centrality of values to societies means that shaping children's values and transmitting value priorities, from one generation to the next are key issues across societies. Value socialization is an ongoing process that takes place in the environment the child encounters, be it in the family, in kindergarten, in school, or in interactions with significant adults and peers.

Values guide behavior and attitudes towards the world and society (e.g., Bardi \& Schwartz, 2003; Knafo, Daniel, \& Khoury-Kassabri, 2008; Vecchione, Döring, Marsicano, Alessandri, \& Bardi, in press), yet little is known about how values develop and how value priorities (i.e., the importance a person may attach to one value or the other) are established. Although there is important research on moral conceptions in childhood (e.g., Nucci, 1982), research typically ignores individuals' values before adolescence (or refers to some normative behaviors as values), because of a theoretical assumption that values are formed mainly in adolescence, and because until recently (Döring, Blauensteiner, Aryus, Drögekamp, \& Bilsky, 2010), no good child scale for assessing values existed. The number of studies conducted on children's values is small, and these studies focused mainly on preadolescence (around age 10 and over) (e.g.,Bilsky et al., 2013; Cieciuch, Döring, \& Harasimczuk, 2012; Döring et al., 2010; Knafo \& Spinath, 2011; Döring et al., 2014). Thus, there is little knowledge about which values children hold, and what the sources for individual differences in children's values are.

Most research on the development and cross-generational continuity of values have focused on the influences of environmental factors such as experience, life events, and exposure to stimuli and situations (see Bardi \& Goodwin, 2011 for an overview) and value priorities have been specifically associated with certain personal attributes such as belonging to a gender (social categorization, Schwartz \& Rubel, 2005), religiosity (Schwartz \& Huismans, 1995), or social class 
(Wright \& Wright, 1976). Yet, values could also be transmitted from parents to children through genes, and that has been largely overlooked (Knafo \& Spinath, 2011)

In the current paper we investigate the genetic and environmental contributions to value priorities of 7year-olds. We aimed to shed light on the genetic contribution to value priorities as well as to expand the age focus that has been covered by previous research to include a unique time in a children's social development when they enter the school system, becoming exposed to a host of new socialization agents, including teachers and peers.

\section{Development of Values}

Despite traditional developmental theories suggesting that children are unable to hold and express abstract beliefs about the social world such as values (Marini \& Case, 1994), recent advances in developmental research and new theories indicate that young children can understand social norms and behavioral standards earlier than previously thought (Thompson, Meyer, \& McGinley, 2006). This change in perspective, as well as recent advances in measurement (Döring, et al., 2010) opened up the possibility to investigate children's values; and how they might differ from or be similar to adult values.

The few studies that examined values in children (e.g., Bilsky et al., 2013; Döring, et al., 2010, 2014; Knafo \& Spinath, 2011) found that value structure at this age is similar to that found in adults, albeit less fine grained. The average age in these studies ranged from 9 to 11, however, so further research is needed with even younger ages to provide insight into the development of value structure and value priorities.

\section{The Structure of Values}

We draw on the conceptualization and operationalization provided by Schwartz's (1992) comprehensive, and widely used (e.g., Boehnke, 2001; Verplanken \& Holland, 2002) account of value priorities and structure. Schwartz (1992) described the value system as composed of ten values, each expressing a specific motivational goal. Actions taken in the pursuit of a certain value carry social and psychological consequences that might be in conflict or may be compatible with 
the pursuit of other values. The total pattern of conflicts and compatibilities among value priorities yields a circular structure of values, wherein motivationally compatible values are located close to one another and motivationally incompatible values opposed to one another (see Figure 1).

The ten values can be arranged along two axes into a higher order structure, resulting in two orthogonal dimensions: Self-enhancement (combining power and achievement values) versus Selftranscendence (universalism and benevolence values) and Openness to change (stimulation and self-direction) versus Conservatism (tradition, security, and conformity values). Hedonism values share aspects of both Openness to change and Self-enhancement (Schwartz, 1992). Both the distinctiveness of the ten values and their theoretical structure have been verified (e.g., Struch, Schwartz, \& van der Kloot, 2002).

Notably, individuals differ in the priorities they assign to each value. Where do individual differences in values come from? Research has typically focused on either demographic attributes or on family influences. More recently, genetics has been proposed to influence individual variability in values (Knafo \& Schwartz, 2009). We conducted the current research with the hypothesis that both environmental and genetic factors are associated with individual differences in value priorities. In the next section we review empirical findings regarding individual characteristics, and then move on to describe research on genetic influences.

\section{Individual Characteristics and Values}

The contribution of the social context to values has been established in adult and adolescent samples (Kohn \& Schooler, 1983; Saroglou, Delpierre, \& Dernelle, 2004; Schwartz \& Rubel, 2005). Here we focus on three main demographic characteristics: gender, socioeconomic status and religiosity.

Gender is one of the most basic social categories, and is associated with different values. A study (Schwartz \& Rubel, 2005) that re-analyzed data from 127 samples from 70 different countries to examine gender effects across cultures found that women ranked Self-transcendence values higher than men, whereas men ranked Self-enhancement values higher than women. Smaller effects 
were found favoring women for Conservation values (with the exception of conformity) and men for Openness to change values. These adult gender differences, though small, were consistent across a wide range of countries and cultures (Longest, Hitlin \& Vaisey, 2013; Schwartz \& RubelLifschitz, 2009; Schwartz \& Rubel, 2005). Similar findings regarding Self-transcendence and Selfenhancement values were reported for adolescents (Knafo \& Schwartz, 2004b). Importantly, in three of the few studies to examine values in children, this pattern of gender differences was replicated (Bilsky, et al., 2013; Döring et al., in press; Knafo \& Spinath, 2011). Children are aware of their gender and the norms associated with gender by age seven (reviewed in Martin, Ruble, \& Szkrybalo, 2002) and therefore we would expect to find the gender-related differentiation of values that is observed in older children and in adults.

Socioeconomic status (SES). Income, education level, and occupation all determine the relative social standing of an individual or a family. People who engage in middle-class occupations that entail higher education levels tend to give higher importance to self-direction and openness to new experiences and knowledge, whereas working-class occupations are associated with more conformist views (Kohn, 1989). There is some evidence from classic studies to support the view that social class influences values (Wright \& Wright, 1976). Importantly, socioeconomic status and parental (especially maternal) education levels and occupation are associated with children's values, and specifically with values on the Conservation to Openness to change axis (Cashmore \& Goodnow, 1986). Additionally, parents' socioeconomic status is related to the values they emphasize when socializing their children. In a recent study of a large group of adolescents, parental education was associated with values most emphasized by parents, as reported by adolescents. Importantly, the values parents emphasized were associated with adolescents' own values (Wray-Lake, Flanagan, Benavides, \& Shubert, 2013). More recently, the association between education and values was further supported in an extremely large data set with over 26,000 participants from 20 European countries (the European Social Survey; ESS). In this study education was associated with higher Openness to change (except for hedonism which correlated negatively) 
and Self-transcendence, and with lower Conservation and achievement (but is not correlated with power) (Longest, Hitlin \& Vaisey, 2013).

Religiosity. Religions hold certain values as more important than others and are often a vessel for disseminating specific values among followers (Schwartz \& Huismans, 1995). As in much previous research on religiosity and values, here we refer to religiosity as self-definition, and not as spirituality or as a specific value. A meta-analysis of studies conducted in 15 different countries and involving the three main monotheistic religions (Christianity, Judaism and Islam) examined the association between values and religiosity (Saroglou, et al., 2004). In these three religions religiosity can be said to involve a sense of belonging to a religious community and participation in religious activities. The meta-analysis concluded that religious people consider values of Conservation as more important and values of Openness to change as less important. Religiosity was also associated, although weakly, with higher benevolence (part of Selftranscendence) and lower Self-enhancement values, as well as lower universalism (although the last effect was very small and associated with specific countries). In the large study of adults across Europe described above, religious participation was again negatively associated with Openness to change and Self-enhancement values, and positively associated with Conservation as well as benevolence (Longest, Hitlin \& Vaisey, 2013). Only one study, to our knowledge, examined the association between values and religiosity in a group of 9-12 year olds. The study defined religiosity more broadly than religious participation, as a combination of the importance given to God in one's life, and the frequency of individual and family prayer. The results of this study resembled findings in adults whereby tradition (part of Conservation) was positively associated with religiosity, whereas hedonism and self-direction (part of Openness to change) were negatively associated with religiosity (Saroglou, 2012). These findings raise an interesting question: Are people drawn into religion due to their values, or does being part of a religion promote certain values in participating individuals (Schwartz, 2012)? This question may be at least partially 
answered in the current study, as the extent to which young children practice religion is usually determined by their parents.

\section{Genetic and Environmental Influences on Values}

Supported by most grand theories of psychology, much theory and research has started from the assumption that family socialization is a key factor in the development of values (e.g., Grusec \& Goodnow, 1994; Knafo \& Schwartz, 2001; Maccoby, 1992). Many studies have shown that children tend to have values similar to those of their parents (Knafo \& Schwartz, 2009; Ranieri \& Barni, 2012; Schönpflug, 2001; Steca, et al., 2012). The resemblance between parents and children might be due to environmental (i.e. demographic) factors (such as the above described demographic variables and more, e.g. parental income level, exposure to similar environments), but also to the genetic similarity between parents and children. Unfortunately, the possibility that parent-child value resemblance results at least partially from genetic similarity between parents and children has been largely ignored (discussed in Knafo \& Schwartz, 2009). However, there are good reasons to hypothesize that values are partially heritable, as they represent the different organismic needs of the person. For example, variation in stimulation values may represent biologically-based temperamental variations in need for excitement and arousal (Schwartz, 1992). Temperamental differences, in turn, are substantially heritable (Plomin, DeFries, McClearn, \& McGuffin, 2008).

Most studies that estimate heritability employ the classic twin design to differentiate between the effects of genetic factors (A), and the effects of the environment, which is in turn divided into shared environment (SE or C) and non-shared environment and error (NSE or E). In this design, monozygotic (MZ) and dizygotic (DZ) twins reared together are assumed to share their environment (SE; e.g., family, neighborhood) to similar degrees. They do differ in their genetic relatedness, as MZ twins share their genetic sequence, while DZ twins only share on average 50\% of the genetic variability (A) (Plomin, et al., 2008). Thus, this design allows estimating the degree to which individual differences are explained by both genetic and environmental factors. 
In the case of values, the empirical evidence is scarce, with all but one study (Knafo \& Spinath, 2011) based on adolescents (Button, Stallings, Rhee, Corley, \& Hewitt, 2011) or adults ( e.g., Schermer, Feather, Zhu, \& Martin, 2008; Waller, Kojetin, Bouchard, Lykken, \& Tellegen, 1990). All studies found a genetic contribution to individual differences in values (accounting for $11 \%$ to $68 \%$ of the variance, with achievement values in Schermer et al., 2008, as an exception). The rest of the variance was explained by the environment. Importantly, these studies demonstrate that the relative contribution of genetics and the SE can vary across values.

An additional level of complexity stems from the findings that heritability and SE effects can also change with age (e.g., Haworth et al., 2009; Knafo \& Plomin, 2006). Indeed, the only genetically-informative study that examined longitudinally the development of values found that the heritability of religious values increased from $29 \%$ to $41 \%$ and a large SE effect of $44 \%$ in adolescence slightly dropped to $37 \%$ in young adulthood (Button et al., 2011). These changes in the genetic and environmental effects on values in adolescence suggest that these effects might be different in childhood than those reported at later ages and in adulthood. The only study to examine heritability of values in childhood (7-11 years old) found moderate heritabilities (28-55\%) for the two Schwartz (1992) value dimensions, with NSE accounting for the remaining variance (Knafo \& Spinath, 2011). As SE effects tend to be larger at younger ages, it is possible that in younger samples different results would emerge. Taken together, this means that to fully understand the role that genetics and environment play in values, it is important to study children who are younger than those studied previously.

\section{The current study}

As described above, only few studies have investigated children's values, but these studies suggest that children have a relatively clear understanding of values and structure them similarly to adults. We aimed to capitalize on the recent introduction of an age-appropriate measure, the PBVS$\mathrm{C}$, to extend these findings in a younger group of children (7 year olds); to examine whether 
children's values resemble those of adults in how they are associated with other variables; and to examine the relative effects of genetic and environmental factors on children's values.

Based on the literature reviewed above, we hypothesized that (1a) as with older samples, Self-enhancement and Self-transcendence would be differentially valued by boys and girls, with the former valued more strongly by boys, and the latter by girls; (1b) a family's religious status would be associated with children's values, with the importance of Conservation higher, and of Openness to change lower, for children raised in more religious settings; (1c) mothers' level of education, would be positively associated with children's Openness to change values, and negatively associated with their Conservation values.

In addition, we aimed to parse out the effects of genes and environment on children's values. Based on adult and adolescent research, we expected both genetic and environmental contribution to children's values. However, we note that this is the youngest sample to date to be tested on the heritability of values. We hypothesized that (2a) individual differences in children's values would be partially explained by genetic factors; ( $2 b)$ environmental contributions, both shared and non-shared, would be found with regards to values. To test our hypothesis, we studied the values of 7-year-old twin children. Addressing a broad set of values enabled us to see whether genetic and environmental influences were similar for the different values.

\section{Methods}

\section{Participants}

348 children (62 MZ pairs and 112 same-sex DZ pairs), 7 years old (90.05 \pm 3.87 months), all Jewish, who were part of the Longitudinal Israeli Study of Twins (LIST, Avinun \& Knafo, 2013) participated. Families were invited to the lab where children were observed performing a variety of tasks. Each child was evaluated separately from his or her twin to avoid any bias effects.

\section{Values Measure}

The Picture-Based Value Survey for Children (Döring, et al., 2010) was specifically designed to study values in childhood. The original German titles were adapted to Hebrew, 
following a translation-back-translation procedure (Brislin, 1980): One bilingual translated from German to Hebrew, and a different bilingual who had not seen the original titles translated the Hebrew titles back to German. A comparison of original and back-translated titles did not yield significant difference, showing that the titles' value-expressive meaning was preserved. With regards to the pictures, few elements were changed, in order to adapt them to children's life in Israel. For example, the cross on the first aid kit was replaced by a Star of David (see Figure 2; 'to help others').

The experimenter invited the child "to take an imaginary journey through things that are important to your life, your goals and how you would like to be in the future". Then children were shown 20 cartoon-like pictures (two for each value type), printed on removable stickers. Each cartoon depicts the same protagonist, performing a value-relevant action, accompanied by a brief caption (Figure 2). An experimenter presented the child with all of the pictures and read each caption out loud. Children were then asked to sort the items according to five levels of importance they ascribe to the values. This allows for two items to be ranked as 'Very important', two as 'Not at all important', then four items are ranked as 'Important' and four items ranked as 'Not important'. The remaining 8 items are ranked in the intermediate level. Thus, each item received a score on a scale of 1 (Not at all important) to 5 (Very important). Previous research (e.g., Döring, et al., 2010) has already established the validity, reliability and suitability of the PBVS-C for middle childhood, and its cross-cultural appropriateness, by showing that the value structure that emerges when using the PBVS-C resembles that of adults, i.e., values that belong to the same higher order value type appear close to each other and the higher order value types form distinct regions. Importantly, Cieciuch et al. (2012) have shown convergence between value priorities when measured by the PBVS-C and the more established Portrait Values Questionnaire (PVQ), thus further supporting the validity of the PBVS-C.

\section{Demographic Data}


Mothers were asked to report their children's gender, as well as their own years of education, and the family's level of religiosity according to commonly accepted categories of religiosity in Israel (1-ultra-orthodox, 2- religious, 3-traditional, 4-secular, 5-other). People who define themselves as either ultra-orthodox or religious are observant and regularly practice Judaism. Those who define themselves as traditional celebrate Jewish holidays and feel close to religion, usually as a family tradition (and hence the name), but do not actively participate daily in religious life. Those who define themselves as secular do not participate regularly in religious practices. Following previous research, family religiosity was then coded as 1=religious (either ultra-orthodox or religious) and $0=$ non-religious (either traditional or secular, Saroglou, et al., 2004). In our sample, $44 \%$ were religious, $54 \%$ were non-religious, and $2 \%$ did not answer the question or used the 'other' category.

\section{Zygosity}

Zygosity was assessed using DNA data (available for $70 \%$ of the participants). For participants without DNA data, zygosity was determined based on a parent questionnaire of physical similarity (Price et al., 2000). In the current sample, the questionnaire was in $95 \%$ agreement with the DNA results (for those participants who had DNA data).

\section{Results}

\section{Children's Value Structure}

Because the current sample is one of the youngest to have used the PBVS-C, we first made sure that children's structure of values corresponds to Schwartz's (1992) prototypical model. For this purpose, we employed theory-based Multidimensional Scaling (MDS) - the procedure that was used in all studies with children (see Döring et al., 2010) and in recent studies with adults (e.g., Schwartz et al., 2012). The MDS represents each value item as a point in a two-dimensional space. The distances between each two items represents the correlation between them: The higher the correlation, the closer together the two items are located. The theory-based MDS lets every item start from its ideal location in Schwartz's (1992) model, which helps avoid local minima (see Borg 
\& Groenen, 2005 for details and Döring et al., 2010 for application to data collected with the PBVS-C). The value structure in Figure 3 closely follows Schwartz' (1992) prototypical model and shows distinct regions for the four higher-order value types. Furthermore, there is a high degree of differentiation within higher-order value types, and the arrangements of regions for the ten value types perfectly matches their ordering around the circle in Schwartz's (1992) model (see Figure 1). That means that the value structure at age 7 reflects the motivational compatibilities and incompatibilities between values in the same way as was found in numerous adult and adolescent samples. In order to assess the fit between the pattern of intercorrelations and their representation in space, we inspected Stress 1 (see Borg \& Groenen, 2005). Stress 1 can take values between 0 and 1; the lower the value, the better the fit. The fit for the configuration in Figure 3 is .208, which indicates a good fit and is considerably lower than the stress for random data (which would be .300 for 20 points to be represented in a two-dimensional space, see Spence \& Ogilvie, 1973). Based on these findings, from here on, we used the four higher order values as our dependent measures, calculated as the mean score of all items belonging to them. They form the two main value dimensions of Openness to change (self-direction, stimulation, and hedonism) versus Conservation (conformity and security), and Self-enhancement (achievement and power) versus Selftranscendence (benevolence and universalism). Thus, the main finding of Figure 3 is that even at this young age children's values form a meaningful structure resembling Schwartz's (1992) theoretical and empirical structure.

\section{Relationships Between Value Priorities and Individual Characteristics}

To examine our first set of hypotheses we used a Generalized Estimating Equations (GEE) model, which controls for the non-independence between two twins from the same family. Examination of association between gender and each of the four higher-order values supported our first hypothesis (1a). As can be seen in Table 1, boys valued Self-enhancement more than girls $\left(\chi^{2}=17.44, p<.001\right)$, whereas girls valued Self-transcendence more than boys $\left(\chi^{2=29.01, p<.001)}\right.$ and no gender effect was observed for Conservation or Openness to change. 
Results for religiosity reflected those found in adults, and supported our second hypothesis that Conservation was valued more by children from religious families $(\mathrm{p}<.001)$, and Openness to change was valued more by children from non-religious families. Self-enhancement and Selftranscendence values did not differ between religious and non-religious families (see Table 1). Mothers' education level, as a proxy of socioeconomic status, was positively associated with Openness to Change, though not with any of the other values (see Table 1), meaning that our third hypothesis was partially supported.

\section{Genetic and Environmental Effects on Values}

Table 2 presents the number of MZ and DZ twins that were included in this analysis. Table 3 shows MZ and DZ correlations for the four higher-order values. Twins, tested separately by different experimenters, showed positive correlations in all values. For all values, except Opennessto-change, MZ correlations are higher, suggesting that at least part of the individual differences in these values is associated with genetic factors. To test this, we conducted an analysis, using the Mx (Neale, Boker, Xie, \& Maes, 1999) and OpenMx (Boker et al., 2011) Structural Equation Modeling (SEM) software packages. These software packages are specifically designed to analyze data from twin studies, estimating the relative contribution of additive genetic (A), shared-environment (SE) and non-shared environment and error (NSE) effects on individual differences in children's values.

The values Self-enhancement, Self-transcendence and Conservation were all best explained by a model that included genetic and non-shared environment effects (see details in Table 3). For Self-enhancement, SE could be dropped from the model without affecting model fit $\left(\chi^{2}(1)\right.$ diff $=.33$, p>.05), therefore the more parsimonious model was selected (AE) with genetic effects estimated at 47\% and NSE estimated at 53\%. Similarly, for Self-transcendence, SE was estimated at 0\% and was therefore dropped from the model without affecting model fit $\left(\chi^{2}(1)\right.$ diff $\left.=.0\right)$ or the point estimates of genetic and NSE effects. Conservation was again first assessed using the complete ACE model, and again, SE was estimated at $0 \%$ and was therefore dropped from the model without affecting modelfit $\left(\chi^{2}(1)\right.$ diff $\left.=.0\right)$ or the point estimates of genetic and NSE effects. 
A different pattern emerged for Openness to Change. The complete ACE model was first estimated, whereby genetic effects (A) were estimated at $0 \%$. Therefore, A was dropped from the model without affecting model fit $\left(\chi_{(1) \text { diff }}^{2}=.0\right)$ or the point estimates of genetic and NSE effects (a model containing NSE only did not fit the data; $\chi^{2}(2)$ diff $\left.=.036\right)$. A model in which no genetic effects were found, whereas individual differences were accounted for by both shared and non-shared environmental effects was therefore most suitable for Openness to change values.

\section{Discussion}

Until very recently, values have been largely considered as later-developing behavioral goals that younger children cannot hold or understand. The structure of the values, and especially the structure of the four higher order values that emerged here, is similar to that observed in adults (Schwartz, 1992), suggesting that children at this early age do understand and attach meaning to values in a manner similar to that of adults. Similarly, overlaps in the association between values and gender, sociocioeconomic status, and religiosity all suggest that children's values have a lot in common with adults' values..

We found that even 7-year-old boys and girls rated differently the values for which gender differences exist in adulthood -Self-transcendence and Self-enhancement - with girls scoring higher on the former and lower on the latter than boys. On the other hand, no difference between boys and girls was observed for Openness to change and Conservation, again, similar to adults, for whom gender differences are weaker on these values. $\backslash$ Gender identity (the ability to recognize oneself and others as 'boy' or 'girl') is formed during early childhood (Martin, Ruble, \& Szkrybalo, 2002). At a later stage children become aware that gender is not only a label, but is associated with norms regarding behavior and attitudes (Frable, 1997). The current finding may mean that 7-yearold children have generalized gender norms to include values, or social norms, and moreover, children have internalized these norms, much in the same way as adults (of course an effect of the biological sex cannot be ruled out). Apart from having a direct effect on values as well as related behaviors, gender may also moderate the association between them. A recent study by Benish- 
Weisman and McDonald (2015) also found that for adolescent girls, unlike boys, there was no association between Self-enhancement and Openness to change values and aggressive behaviors (as measured by peer-nominations). Taken together, these findings emphasize the complex nature of gender differences.

Girls and boys are exposed from a very young age to gender stereotypes in the family and in child-care settings, and are exposed to different demands regarding prosocial and aggressive behavior (Chick, Heilman-Houser, \& Hunter, 2002). Children soon adapt behaviors and views that are associated with their gender roles, and these views of right and wrong, what is acceptable and what is not, influence the way they grow up to see the world, what values they adopt and how they behave. Indeed, physical aggression, for example, tends to be higher for boys (Zimmer-Gembeck, Geiger, \& Crick, 2005, and is positively associated with the Self-enhancement value of power (Knafo, Daniel, \& Khoury-Kassabri, 2008). Similarly, prosocial behavior tends to be higher for girls (Zimmer-Gembeck, Geiger, \& Crick, 2005) and is associated with the Self-transcendence value of benevolence (reviewed in Schwartz, 2010). This suggest a complex relationship throughout early development between internalizing gender roles, shaping one's view of what is most important, and acting in the world. Because gender roles are already established to some extent in early childhood (Martin, Ruble, \& Szkrybalo, 2002), it is plausible that value priorities development is influenced by already established gender roles. Future research on younger children would benefit from studying at what age value priorities become influenced by gender and whether the process by which this comes about is similar to or different from other social norms associated with gender.

Socioeconomic status, as indexed by maternal education, was associated with higher Openness to change, in line with findings from adults (Cashmore \& Goodnow, 1986). The current findings differed with respect to Conservation and possibly Self-transcendence, which were expected to be negatively associated with maternal education (Longest, Hitlin \& Vaisey, 2013), but were not associated with maternal education at all. This finding means that although children's 
values are similar to those of adults, they are not the same, and further processes (e.g., influence of socioeconomic status on Conservation) are likely to take place in later ages.

In the case of religiosity, we found that, as expected, children from religious families valued Conservation more and Openness to change less than children from non-religious families. These findings entirely replicate findings from adult Christian, Muslim, and Jewish samples (Longest, Hitlin \& Vaisey, 2013; Saroglou, et al., 2004), suggesting that religion has a conduit role in transmitting Openness to change-Conservation values from parents to children. This effect of parents may be indirect, and could be mediated by environments that parents choose for their children, such as religious schools (Knafo, 2003). Indeed, one consistent finding is that religious and tradition values both show SE effects (Button, et al., 2011; Renner et al., 2012; Schermer, et al., 2008). The SE effect on tradition may be stronger than for most other values, as tradition values are more strongly tied to families' demographic background (i.e., environmental effects) and more observable in parents' behavior (religiosity is usually related to religious practices such as attending religious ceremonies and observing religious holidays, and not to spirituality); this may account in part for the typical finding of higher similarity between parents and their children on tradition relative to other values (Knafo \& Schwartz, 2009). Similarly, restrictive parenting measured in early childhood was found to show a positive correlation with conformity values and a negative correlation with self-direction values measured 26 years later (Kasser et al., 2002), suggesting that these values can be influenced by environmental factors (although genetic effects may also play a role through a gene-environment correlation).

The observed association between religiosity and values in children brings us closer to answering the question of whether values stem from being religious (values as consequence of religion), or whether certain values drive us towards religion (religion as consequence of values). The current study suggests that the first, values as consequence, might be true. Young children, as opposed to adults, have little control over their families' religious status. Therefore, the fact that a family's religious status is associated with a child's values suggests that religion promotes higher 
Conservation and lower Openness to change. Moreover, this suggests that the effects of religion are far-reaching, and may affect our behavior outside the scope of religious life, through fostering of specific values, that influence behavior in broader contexts.

It would be interesting in future research to see whether the early effects of religiosity on children's values are unique to the current, Jewish sample. For observant Jews, religious practice is a core component of everyday life, and religious demands are placed on children from a very young age, such as saying a prayer before every meal, accompanying parents to synagogue, refraining from using electricity on the Sabbath (e.g., watching television, turning on the lights, etc.), and observing dietary restrictions (e.g., a period of several hours must pass before eating dairy after consuming meat products). These restrictions are part of children's daily life. Thus, in observant families, religion is present all the time, and children who grow up in religious families are likely to be exposed to their parents' conservative values.

The second part of the study focused on parsing out the genetic and environmental effects on each of the values. Again, findings resembled those found in adults, with children's Selftranscendence, Self-enhancement and Conservation values being affected moderately by genetic factors as well as non-shared environment and error (the magnitude of which is similar to what was found in previous research; e.g., Button, Stallings, Rhee, Corley, \& Hewitt, 2011; Knafo \& Spinath, 2011; Schermer et al., 2008; Waller, Kojetin, Bouchard, Lykken, \& Tellegen, 1990), suggesting that a significant portion of the individual variance in children's values can be attributed to genetic factors. Conversely, the best fitting model for Openness to change included only environmental effects, and genetic factors could not account for any of the variance in this value. Interestingly, the only value that was associated with the two environmental factors that were examined here (socioeconomic status and religiosity) was Openness to Change. This may suggest that Openness to change values, especially at this age, are affected by environmental factors whereas genetics and temperament come into play only later in life. 
Importantly, the only other published genetic study of children's values (Knafo \& Spinath, 2011) did find a genetic effect on the Openness-Conservation dimension (the two values were examined jointly), albeit with slightly older children (7-11 year olds). This apparent discrepancy might be explained by the different age groups examined in the two studies. SE effects tend to appear early and decrease with age (Knafo \& Plomin, 2006; Knafo, Zahn-Waxler, Van Hulle, Robinson, \& Rhee, 2008). Similarly, although DNA composition is determined at conception, genetic effects may change through life. As many studies show (Haworth, et al., 2009; Plomin, et al., 2008), the heritability of traits tends to increase with age. Thus, genetic effects on Openness may emerge later in life. One reason for SE becoming less influential is that, as children grow up, they become more independent and encounter increasingly diverse and differentiated environments, which lead them to develop differently. Indeed, children at the age of the current sample experience new stimuli constantly, but almost always it is done in a way that is controlled and directed by the environment - parents, teachers, or other adults. Children at this age have little opportunity to explore and think about the importance of controlling their own lives. As they grow into preadolescence and adolescence, it is possible that these become increasingly important, the environment becomes less restrictive and they are afforded more independence. Therefore, only then can they start to express their genetic inclinations. More generally, the increase in heritability may reflect a process in which children's genetically-influenced value-based behaviors initiate chains of environmental events, such as reactions from parents and peers. These are evocative geneenvironment correlations, as peer/parent reactions are correlated with the child's genotype. These effects can then feed back towards children's own behavior, thereby increasing the observed relative importance of genetics to individual differences (Beam \& Turkheimer, 2013; Knafo \& Jaffee, 2013). For example, consider a child who is curious and open by nature, as she grows older she is freer to express behavior associated with Openness to change values. The environment (parents, teachers, peers, etc.) may respond by nurturing that curiosity thereby fostering these values. 
Research often tends to interpret heritability estimates as reflecting a stable characteristic of the examined phenomenon. However, in order to fully understand the genetic and environmental etiologies of a phenomenon, one must examine it longitudinally throughout development, and future studies may benefit from such an endeavor. With regards to the current investigation of values, it is also important to note that each of the higher order values might follow a different developmental pattern, and be affected by genetics and environmental factors to a differing extent at different ages. Specifically, adolescence, as an important period for identity formation, may be a life period in which values are reconsidered, and research on the genetic and environmental factors involved in children's values as they transition to adolescence is needed to bridge the prevalent conceptions of values as formed in adolescence with the current findings of genetically-influence values present in middle childhood.

\section{Limitations and Future Directions}

The current study focuses on value preference in 7-year-old twins. In order to better understand the developmental aspect, a longitudinal study of value development is in order. Previous studies of value heritability used questionnaire measures to assess values. Here, we used a measure of values that is based on children's real-time decisions regarding what they see as important. Our sample size (384 children) could have been a problem for genetic research, because smaller sample sizes often make it harder to accurately estimate the effects that contribute to similarity between the twins (the relative contribution of genetics vs. shared environment). However, in the current study, for most higher-order values the correlation between MZ twins was much higher than the correlation between DZ twins, with no evidence for shared environment effects. Thus we had sufficient power to attribute the similarity between twins to genetic factors.

We did not have enough power to examine a 'sex-limitation' model, which allows an examination of the contribution of genetic and environmental factors to each gender separately. Based on the difference between boys and girls for Self-enhancement and Self-transcendence values, it would be worthwhile for future studies with larger sample sizes to examine this issue. 
Another important avenue for future research would be to examine specifically how genes influence value priorities. The answers may come from two avenues of research. The first would be to investigate the role of specific genes in value priorities. For example, prosocial behavior (Israel et al. Lerer et al., 2008) and empathy (Uzefovskyet al., 2015) have been linked to the oxytocinvasopressin system, which may have a role in the importance one attaches to the corresponding values of Self-transcendence. The second avenue of research would be to explore how temperament and personality may mediate the association between genes and values. Studies have consistently established the association between genes and personality dimensions (reviewed in Plomin, Caspi, Pervin, \& John, 1999) as well as the association between personality and values (reviewed in ParksLeduc, Feldman, \& Bardi, 2015). These findings, together with the early emergence of temperament and personality traits (e.g., Rothbart, 1981) suggest that personality may mediate the association between genes and values, and these should be studied together at younger ages.

Having demonstrated that overall, the structure of values and their relationship with other variables is very similar for adulthood and middle childhood, our findings raise further important theoretical and empirical considerations. Values change in importance from middle childhood to adolescence (Cieciuch, Davidov, \& Algesheimer, in press) and continue to develop and change throughout adolescence, and possibly beyond (Daniel, Dys, Buchmann, \& Malti, in press). It is important to investigate value development across childhood and adolescence, and hopefully from a lifespan perspective too.

Future studies would benefit from examining what characterizes children's values as opposed to the fully developed values held by adults. What happens before the age of 7 ? When do value concepts first start to develop? Moreover, how do these concepts develop and mature over time? Is it possible to measure more rudimentary forms of values as basic motivational goals in early childhood? And how do genetic and environmental factors work together to shape a child's value profile? The current study fills a gap that exists regarding the understanding of the structure and function of values in younger children. Values are integral to our social decision making and 
ultimately, social behavior. Hence, a greater understanding of how values develop and how this may be influenced by genes and environmental influences essentially provides a better understanding of the process by which children's social world is shaped.

\section{Acknowledgements}

The authors are indebted to the parents and twins in the Longitudinal Israeli Study of Twins (LIST) for making the study possible. We also thank the research assistants who helped collect the data. Data collection was supported by a grant from The Science of Generosity Initiative, funded by the John Templeton Foundation to Ariel Knafo. Preparation of this manuscript was supported by grant No. 1670/13 from the Israel Science Foundation to Ariel Knafo. Florina Uzefovsky was supported by the Adrienne de Rothschild fellowship, by the Israel Science Foundation (grant No. 449/14), by the British Friends of Hebrew University and by the Joseph Levy fellowship. 


\section{References}

Avinun, R., \& Knafo, A. (2013). The Longitudinal Israeli Study of Twins (LIST): An integrative view of social development. Twin Research and Human Genetics, 1, 1-5. doi: http://dx.doi.org/10.1017/thg.2012.73

Bardi, A., \& Goodwin, R. (2011). The dual route to value change: Individual processes and cultural moderators. Journal of Cross-Cultural Psychology, 42, 271-287. doi: $10.1177 / 0022022110396916$

Bardi, A., \& Schwartz, S. H. (2003). Values and behavior: strength and structure of relations. Personality and Social Psychology Bulletin, 29, 1207-1220. doi: $10.1177 / 0146167203254602$

Beam, C. R., \& Turkheimer, E. (2013). Phenotype-environment correlations in longitudinal twin models. Development and Psychopathology, 25, 7-16. doi: 10.1017/S0954579412000867

Benish-Weisman, M., \& McDonald K.L. (2015). Private Self-consciousness and Gender Moderate How Adolescents' Values Relate to Aggression. Social Development, in press. doi: $10.1111 /$ sode. 12122

Bilsky, W., Döring, A. K., van Beeck, F., Rose, I., Schmitz, J., Aryus, K., . . Sindermann, J. (2013). Assessment of children's value structures and value preferences: Testing and expanding the limits. Swiss Journal of Psychology, 72(3), 123-136. doi: 10.1024/14210185/a000106

Boehnke, K. (2001). Parent-offspring value transmission in a societal context: Suggestions for a utopian research design - with empirical underpinnings. Journal of Cross-Cultural Psychology, 32, 241-255. doi: 10.1177/0022022101032002010

Boker, S., Neale, M., Maes, H., Wilde, M., Spiegel, M., Brick, T., . . Bates, T. (2011). OpenMx: an open source extended structural equation modeling framework. Psychometrika, 76, 306317. doi: 10.1007/s11336-010-9200-6 
Borg, I., \& Groenen, P. J. F. (2005). Modern multidimensional scaling: Theory and applications. New York: Springer.

Brislin, R. W. (1980). Translation and content analysis of oral and written material. In H. C. Triandis J. W. Berry (Eds.), Handbook of cross-cultural psychology (Vol. 2, pp. 349-444). Boston, MA: Allyn \& Bacon.

Brosch, T., Coppin, G., Scherer, K. R., Schwartz, S., \& Sander, D. (2011). Generating value(s): Psychological value hierarchies reflect context-dependent sensitivity of the reward system. Social Neuroscience, 6, 198-208. doi: 10.1080/17470919.2010.506754

Button, T. M., Stallings, M. C., Rhee, S. H., Corley, R. P., \& Hewitt, J. K. (2011). The etiology of stability and change in religious values and religious attendance. Behavior Genetics, 41, 201-210. doi: 10.1007/s10519-010-9388-3

Cashmore, J. A., \& Goodnow, J. J. (1985). Agreement between generations: A two-process approach. Child Development, 56, 493-501. doi: 10.2307/1129736

Cashmore, J. A., \& Goodnow, J. J. (1986). Influences on Australian parents' values: ethnicity versus socioeconomic status. Journal of Cross-Cultural Psychology, 17, 441-454. doi: $10.1177 / 0022002186017004004$

Chick K.A., Heilman-Houser R.A., \& Hunter M. W. (2002) The Impact of Child Care on Gender Role Development and Gender Stereotypes. Early Childhood Education Journal, 29, 149154. doi: 10.1023/A:1014528424032

Cieciuch, J., Davidov, E., \& Algesheimer, R. (2015). Development of value priorities in childhood: A longitudinal study. Social Development, in this special section.

Cieciuch, J., Döring, A. K., \& Harasimczuk, J. (2012). Measuring Schwartz's values in childhood: Multidimensional scaling across instruments and cultures. European Journal of Developmental Psychology, 10, 625-633. doi: 10.1080/17405629.2012.707779 
Daniel, E., Dys, S.P., Buchmann, M., \& Malti, T. (2015). Developmental trajectories of social justice values in adolescence: Relations with sympathy and friendship quality, Social Development, in this special section.

Döring, A. K., Blauensteiner, A., Aryus, K., Drögekamp, L., \& Bilsky, W. (2010). Assessing values at an early age: the Picture-Based Value Survey for Children (PBVS-C). Journal of Personality Assessment, 92, 439-448. doi: 10.1080/00223891.2010.497423

Döring, A. K., Schwartz, S. H., Cieciuch, J., Groenen, P. J. F., Glatzel, V., Harasimczuk, J., Janowicz, N., Nyagolova, M., Scheefer, E. R., Allritz, M., Milfont, T. L., \& Bilsky, W. (in press). Crosscultural evidence of value structures and priorities in childhood. British Journal of Psychology.

Frable, D. E. (1997). Gender, racial, ethnic, sexual, and class identities. Annual review of psychology, 48(1), 139-162. doi: 10.1146/annurev.psych.48.1.139

Grønhøj, A., \& Thøgersen, J. (2009). Like father, like son? Intergenerational transmission of values, attitudes, and behaviours in the environmental domain. Journal of Environmental Psychology, 29, 414-421. doi: 10.1016/j.jenvp.2009.05.002

Grusec, J. E., \& Goodnow, J. J. (1994). Impact of parental discipline methods on the child's internalization of values: A reconceptualization of current points of view. Developmental Psychology, 30, 4. doi: 10.1037/0012-1649.30.1.4

Guimond, S., Chatard, A., Martinot, D., Crisp, R. J., \& Redersdorff, S. (2006). Social comparison, self-stereotyping, and gender differences in self-construals. Journal of Personality and Social Psychology, 90, 221. doi: 10.1037/0022-3514.90.2.221

Haworth, C., Wright, M., Luciano, M., Martin, N., De Geus, E., Van Beijsterveldt, C., ... Davis, O. (2009). The heritability of general cognitive ability increases linearly from childhood to young adulthood. Molecular Psychiatry, 15, 1112-1120. doi: 10.1038/mp.2009.55

Israel, S., Lerer, E., Shalev, I., Uzefovsky, F., Reibold, M., Bachner-Melman, R., ... \& Ebstein, R. P. (2008). Molecular genetic studies of the arginine vasopressin 1a receptor (AVPR1a) and 
the oxytocin receptor (OXTR) in human behaviour: from autism to altruism with some notes in between. Progress in brain research, 170, 435-449. doi:10.1016/S0079-6123(08)00434-2

Kasser, T., Koestner, R., \& Lekes, N. (2002). Early family experiences and adult values: a 26-year prospective longitudinal study. Personality and Social Psychology Bulletin, 28, 826-835. doi: $10.1177 / 0146167202289011$

Knafo, A. (2003). Contexts, relationship quality, and family value socialization: The case of parentschool ideological fit in Israel. Personal Relationships, 10, 371-388. doi: 10.1111/14756811.00055

Knafo, A., Daniel, E., Gabay, S., Zilber, R., \& Shir, R. (2012). Religion and the intergenerational continuity of values. In G. Trommsdorff \& X. Chen (Eds.), Values, religion, and culture in adolescent development (pp. 370-390). New York: Cambridge University Press.

Knafo, A., Daniel, E., \& Khoury-Kassabri, M. (2008). Values as protective factors against violent behavior in Jewish and Arab high schools in Israel. Child Development, 79, 652-667. doi: 10.1111/j.1467-8624.2008.01149.x

Knafo, A., \& Jaffee, S. R. (2013). Gene-environment correlation in developmental psychopathology. Development and Psychopathology, 25, 1-6. doi: $10.1017 / \mathrm{S} 0954579412000855$

Knafo, A., \& Plomin, R. (2006). Prosocial behavior from early to middle childhood: genetic and environmental influences on stability and change. Developmental Psychology, 42, 771-786. doi: $10.1037 / 0012-1649.42 .5 .771$

Knafo, A., \& Schwartz, S. H. (2001). Value socialization in families of Israeli-born and Soviet-born adolescents in Israel. Journal of Cross-Cultural Psychology, 32, 213-228. doi: $10.1177 / 0022022101032002008$

Knafo, A., \& Schwartz, S. H. (2004a). Identity formation and parent-child value congruence in adolescence. British Journal of Developmental Psychology, 22, 439-458. doi: $10.1348 / 0261510041552765$ 
Knafo, A., \& Schwartz, S. H. (2004b). Value transmission in the family: Effects of family background and implications for educational achievement. Paper presented at the National Council of Jewish Women, Research Institute for Innovation in Education, Jerusalem, Israel.

Knafo, A., \& Schwartz, S. H. (2009). Accounting for parent-child value congruence: theoretical considerations and empirical evidence cultural transmission. In Schönpflug, U. (Ed.), Cultural transmission: psychological, developmental, social, and methodological aspects (pp. 240-268). New York: Cambridge University Press.

Knafo, A., \& Spinath, F. (2011). Genetic and environmental influences on girls' and boys' gendertyped and gender-neutral values. Developmental Psychology, 47, 726-731. doi: $10.1037 / \mathrm{a} 0021910$

Knafo, A., Zahn-Waxler, C., Van Hulle, C., Robinson, J. L., \& Rhee, S. H. (2008). The developmental origins of a disposition toward empathy: Genetic and environmental contributions. Emotion, 8, 737-752. doi: 2008-17541-001 [pii] 10.1037/a0014179

Kohn, M. (1989). Class and conformity: a study in values. Chicago: University of Chicago Press.

Kohn, M. L., \& Schooler, C. (1983). Work and personality: An inquiry into the impact of social stratification. Norwood, NJ: Ablex Publishing Corporation.

Longest, K. C., Hitlin, S., \& Vaisey, S. (2013). Position and disposition: the contextual development of human values. Social Forces, 91(4), 1499-1528. doi: 10.1093/sf/sot045

Maccoby, E. E. (1992). The role of parents in the socialization of children: An historical overview. Developmental Psychology, 28, 1006-1017. doi: 10.1037/0012-1649.28.6.1006

Marini, Z., \& Case, R. (1994). The development of abstract reasoning about the physical and social world. Child Development, 65(1), 147-159. doi: 10.2307/1131372

Martin, C. L., Ruble, D. N., \& Szkrybalo, J. (2002). Cognitive theories of early gender development. Psychological Bulletin, 128, 903-933. doi: 10.1037/0033-2909.128.6.903

Neale, M. C., Boker, S. M., Xie, G., \& Maes, H. H. (1999). Mx: statistical modeling. VCU Box, 900126, Richmond, VA 23298: Department of Psychiatry. 
Nucci, L. P. (1982). Conceptual development in the moral and conventional domains: implications for values education. Review of Educational Research, 52, 93-122. doi: $10.3102 / 00346543052001093$

Parks-Leduc, L., Feldman, G., \& Bardi, A. (2015). Personality Traits and Personal Values: A MetaAnalysis. Personality and Social Psychology Review, 19(1). doi: 0.1177/1088868314538548

Plomin, R., Caspi, A., Pervin, L. A., \& John, O. P. (1999). Behavioral genetics and personality. Handbook of personality: Theory and research, 2, 251-276.

Plomin, R., DeFries, J., McClearn, G., \& McGuffin, P. (2008). Behavioral genetics. New York: Worth Publishers.

Price, T. S., Freeman, B., Craig, I., Petrill, S. A., Ebersole, L., \& Plomin, R. (2000). Infant zygosity can be assigned by parental report questionnaire data. Twin Research, 3(3), 129-133. doi: 10.1375/twin.3.3.129

Ranieri, S., \& Barni, D. (2012). Family and other social contexts in the intergenerational transmission of values. Family Science, 3, 1-3. doi: 10.1080/19424620.2012.714591

Renner, W., Kandler, C., Bleidorn, W., Riemann, R., Angleitner, A., Spinath, F. M., \& MenschikBendele, J. (2012). Human values: genetic and environmental effects on five lexically derived domains and their facets. Personality and Individual Differences, 52, 89-93. doi: http://dx.doi.org/10.1016/j.paid.2011.09.003

Roccas, S., Sagiv, L., Schwartz, S., \& Knafo, A. (2002). The big five personality factors and personal values. Personality and Social Psychology Bulletin, 28, 789. doi: $10.1177 / 0146167202289008$

Rothbart, M. K. (1981). Measurement of temperament in infancy. Child Development, 569-578. Saroglou, V., Delpierre, V., \& Dernelle, R. (2004). Values and religiosity: a meta-analysis of studies using Schwartz's model. Personality and Individual Differences, 37, 721-734. doi: http://dx.doi.org/10.1016/j.paid.2003.10.005 
Saroglou, V. (2012). Adolescents' Social Development and the Role of Religion Coherence at the Detriment of Openness. In G. Tromsdorff and S. Chen (Eds.), Values, religion, and culture in adolescent development (pp. 391-423). New York: Cambridge University Press.

Schermer, J. A., Feather, N. T., Zhu, G., \& Martin, N. G. (2008). Phenotypic, genetic, and environmental properties of the Portrait Values Questionnaire. Twin Research and Human Genetics, 11, 531-537. doi:10.1375/twin.11.5.531

Schönpflug, U. (2001). Intergenerational transmission of values: the role of transmission belts. Journal of Cross-Cultural Psychology, 32, 174-185. doi: 10.1177/0022022101032002005

Schwartz, S. H. (1992). Universals in the content and structure of values: theoretical advances and empirical tests in 20 countries. Advances in Experimental Social Psychology, 25, 1-65.

Schwartz, S. H. (2010). Basic values: How they motivate and inhibit prosocial behavior. Prosocial motives, emotions, and behavior: The better angels of our nature, 14, 221-241. doi: $10.1037 / 12061-012$

Schwartz, S. H. (2012). Values and religion in adolescent development: cross-national and comparative evidence. In G. Tromsdorff and S. Chen (Eds.), Values, religion, and culture in adolescent development (pp. 97-122). New York: Cambridge University Press.

Schwartz, S. H., \& Bardi, A. (2001). Value hierarchies across cultures: taking a similarities perspective. Journal of Cross-Cultural Psychology, 32, 268-290. doi:

$10.1177 / 0022022101032003002$

Schwartz, S. H., Cieciuch, J., Vecchione, M., Davidov, E., Fischer, R., Beierlein, C., ... Demirutku, K. (2012). Refining the theory of basic individual values. Journal of Personality and Social Psychology, 103, 663-688. doi: 10.1037/a0029393

Schwartz, S. H., \& Huismans, S. (1995). Value priorities and religiosity in four Western religions. Social Psychology Quarterly, 58, 88-107. doi: 10.2307/2787148 
Schwartz, S. H., \& Rubel-Lifschitz, T. (2009). Cross-national variation in the size of sex differences in values: effects of gender equality. Journal of Personality and Social Psychology, 97, 171185. doi: $10.1037 / \mathrm{a} 0015546$

Schwartz, S. H., \& Rubel, T. (2005). Sex differences in value priorities: cross-cultural and multimethod studies. Journal of Personality and Social Psychology, 89, 1010-1028. doi: 10.1037/0022-3514.89.6.1010

Schwartz, S. H., \& Sagiv, L. (1995). Identifying culture-specifics in the content and structure of values. Journal of Cross-Cultural Psychology, 26, 92-116. doi: 10.1177/0022022195261007

Spence, I., \& Ogilvie, J. C. (1973). A table of expected stress values for random rankings in nonmetric multidimensional scaling. Multivariate Behavioral Research, 8, 511-517. doi: 10.1207/s15327906mbr0804_8

Steca, P., Monzani, D., Greco, A., \& D'Addario, M. (2012). Similarity in self-enhancement and self-transcendence values between young adults and their parents and friends. Family Science, 3, 34-45. doi: 10.1080/19424620.2011.704772

Struch, N., Schwartz, S. H., \& van der Kloot, W. A. (2002). Meanings of basic values for women and men: a cross-cultural analysis. Personality and Social Psychology Bulletin, 28, 16-28. doi: $10.1177 / 0146167202281002$

Thompson, R. A., Meyer, S., \& McGinley, M. (2006). Understanding values in relationship: The development of conscience. In M. Killen \& J. Smetana (Eds.), Handbook of moral development (pp. 267-297). Mahwah, NJ: Erlbaum.

Uzefovsky, F., Shalev, I., Israel, S., Edelman, S., Raz, Y., Mankuta, D. ... \& Ebstein, R. P. (2015). Oxytocin receptor and vasopressin receptor 1a genes are respectively associated with emotional and cognitive empathy. Hormones and Behavior, 67, 60-65. doi:10.1016/j.yhbeh.2014.11.007 
Vecchione, M., Döring, A. K., Marsicano, G., Alessandri, G., \& Bardi, A. (2015). Reciprocal relations across time between basic values and value-expressive behaviors: A longitudinal study among children. Social Development, in this special section.

Verplanken, B., \& Holland, R. W. (2002). Motivated decision making: effects of activation and self-centrality of values on choices and behavior. Journal of Personality and Social Psychology, 82, 434-447. doi: 10.1037/0022-3514.82.3.434

Waller, N. G., Kojetin, B. A., Bouchard, T. J., Lykken, D. T., \& Tellegen, A. (1990). Genetic and environmental influences on religious interests, attitudes, and values: a study of twins reared apart and together. Psychological Science, 1, 138-142. doi: 10.1111/j.14679280.1990.tb00083.x

Wright, J. D., \& Wright, S. R. (1976). Social class and parental values for children: A partial replication and extension of the Kohn thesis. American Sociological Review, 41, 527-537.

Zimmer-Gembeck, M. J., Geiger, T. C., \& Crick, N. R. (2005). Relational and Physical Aggression, Prosocial Behavior, and Peer Relations Gender Moderation and Bidirectional Associations. The Journal of Early Adolescence, 25(4), 421-452. doi: 10.1177/0272431605279841 
Table 1

Effects of Gender, Religiosity and Mother's Education on Children's Value Priorities

\section{Religiosity effect $(\mathrm{N}=295)$}

Mothers'

Value

Gender effect $(\mathrm{N}=394)$

education level

$(\mathrm{N}=303)$

\begin{tabular}{cccccccccc}
\hline Male & Female & $X^{2}$ & Sig. & Religious & Non- & $X^{2}$ & Sig & Beta & Sig. \\
Mean & Mean & & $p$ & Mean & religious & & $P$ & \\
$( \pm . \mathrm{SE})$ & $( \pm . \mathrm{SE})$ & & & $( \pm . \mathrm{SE})$ & Mean & & & \\
& & & & & & & \\
& & & & & & & & \\
& & & & & & & &
\end{tabular}

\begin{tabular}{|c|c|c|c|c|c|c|c|c|c|c|}
\hline $\begin{array}{l}\text { Self- } \\
\text { enhancem }\end{array}$ & $\begin{array}{r}2.65 \\
( \pm .05)\end{array}$ & $\begin{array}{r}2.34 \\
( \pm .05)\end{array}$ & 17.44 & $<.001$ & $\begin{array}{l}2.43 \\
( \pm .06)\end{array}$ & $\begin{array}{r}2.51 \\
( \pm .06)\end{array}$ & .65 & .362 & $\begin{array}{c}- \\
.009\end{array}$ & .613 \\
\hline \multicolumn{11}{|l|}{ ent } \\
\hline Self- & 3.21 & 3.48 & 29.01 & $<.001$ & 3.40 & 3.34 & .19 & .311 & - & .291 \\
\hline transcende & $( \pm .04)$ & $( \pm .03)$ & & & $( \pm .04)$ & $( \pm .05)$ & & & .011 & \\
\hline \multicolumn{11}{|l|}{ nce } \\
\hline Conservati & 3.20 & 3.24 & .80 & .371 & 3.35 & 3.13 & 24.9 & $<.00$ & - & .256 \\
\hline on & $( \pm .03)$ & $( \pm .03)$ & & & $( \pm .03)$ & $( \pm .04)$ & 1 & 1 & .012 & \\
\hline Openness & 2.90 & 2.88 & .20 & .653 & 2.76 & 2.97 & 15.2 & $<.00$ & .024 & $<.05$ \\
\hline to change & $( \pm .03)$ & $( \pm .03)$ & & & $( \pm .04)$ & $( \pm .03)$ & 3 & 1 & & \\
\hline
\end{tabular}

Note. Analyses were conducted using Generalized Estimating Equations. 
Table 2

The composition of the sample by zygosity and gender

\begin{tabular}{l|lll} 
& Male & Female & Total \\
\hline MZ & 62 & 62 & 124 \\
DZ-s & 114 & 110 & 224 \\
Total & 176 & 172 & 348
\end{tabular}

Note $. \mathrm{MZ}=$ monozygotic, $\mathrm{DZ}-\mathrm{s}=$ dizygotic, same-sex twins. 
Table 3

Twin Correlations and Genetic/Environmental Influences on the Importance Given to Values

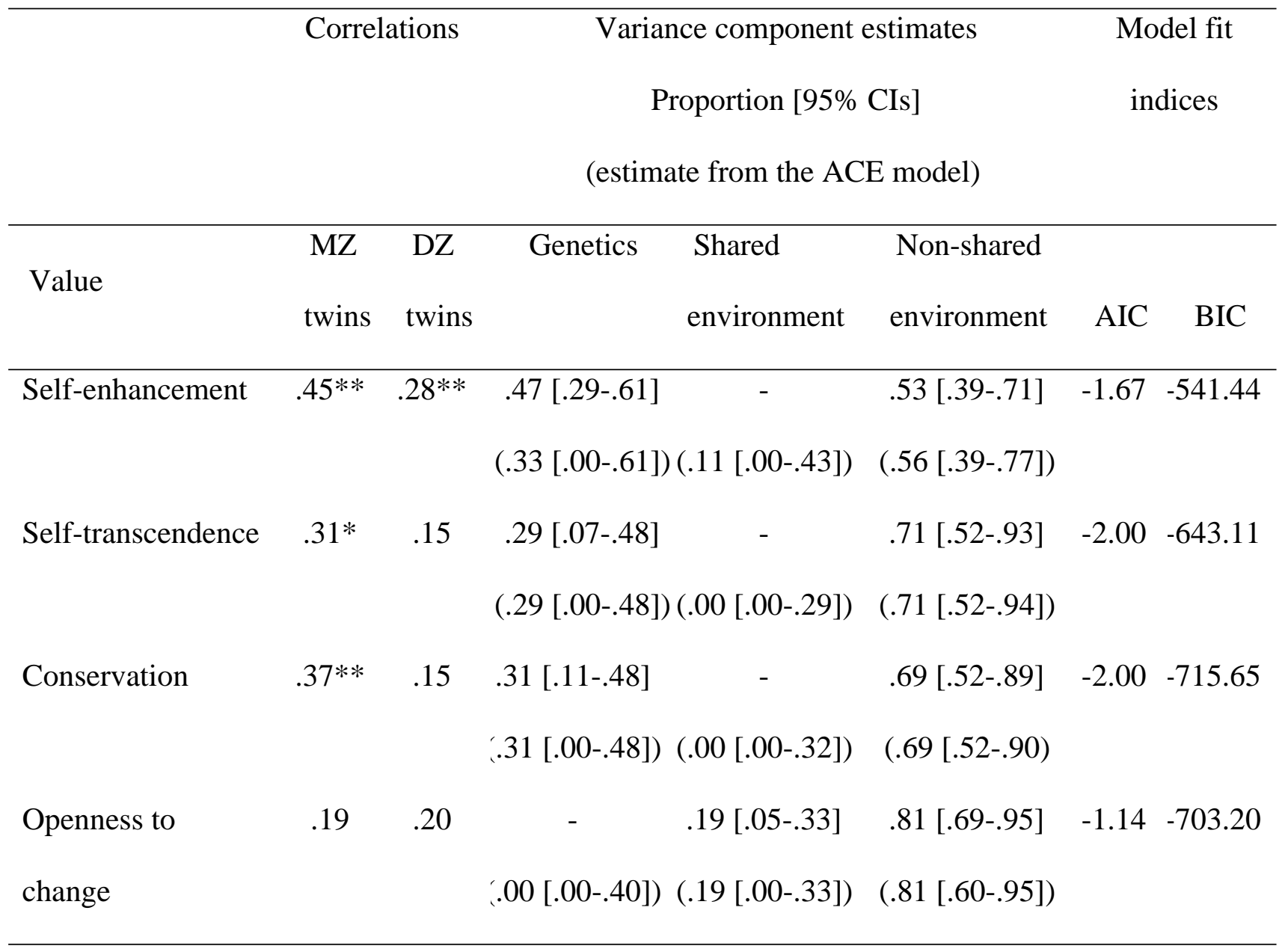

Note. $\mathrm{MZ}=$ monozygotic, $\mathrm{DZ}=$ dizygotic, same-sex twins. ${ }^{*} \mathrm{p}<.05, * * \mathrm{p}<.01$. Estimates from the full ACE model appear in parenthesis for the effect of Genetics, Shared environment and Non-shared environment. $\mathrm{AIC}=$ Akaike information criterion, calculated in comparison to the full ACE model. $\mathrm{BIC}=$ Bayesian information criterion. Controlling for gender did not alter the estimates in any meaningful way. 


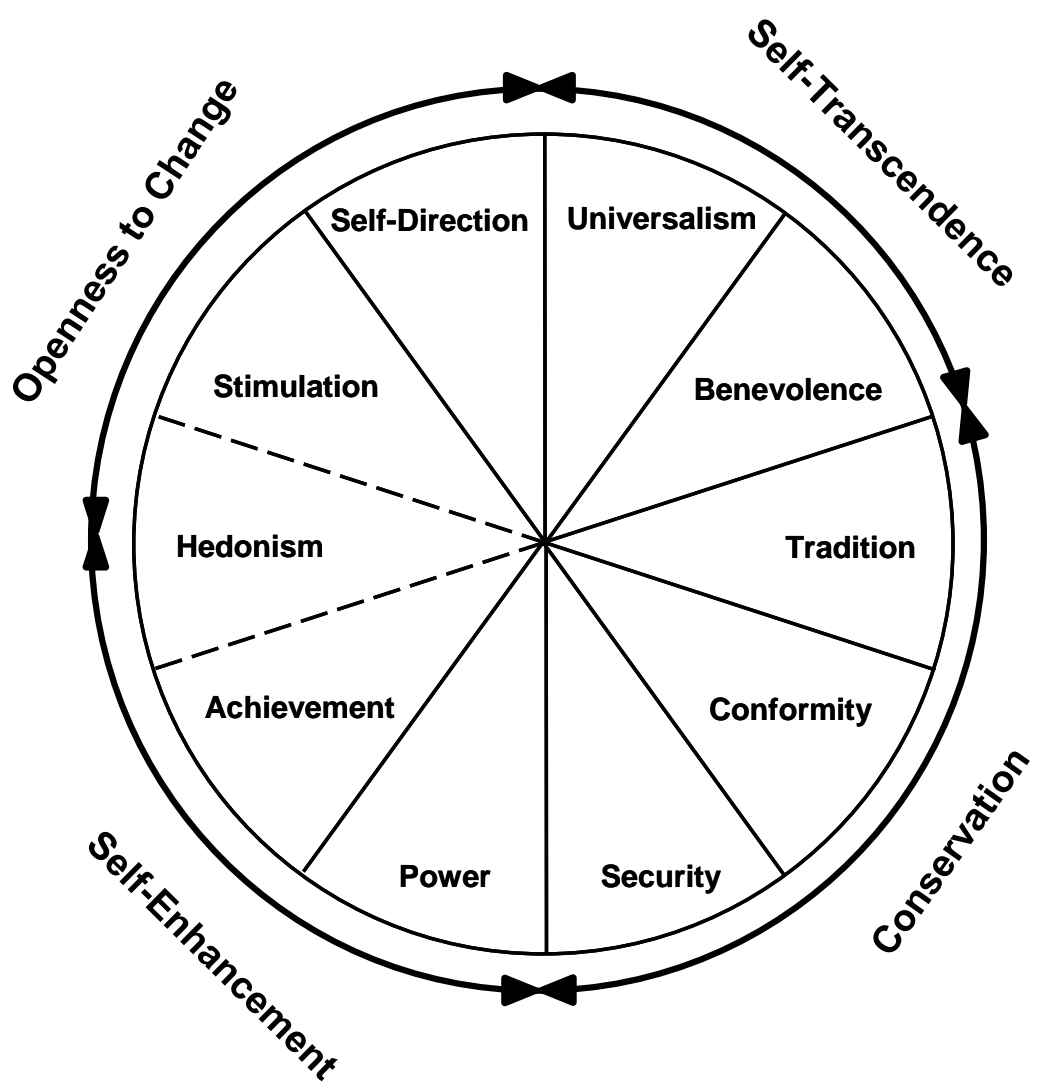

Figure 1. Theoretical and empirical structure of relations among the ten basic human values and the four higher order values. Values which are closer to each other are more compatible than values which are further apart (Schwartz, 1992, p. 14). 


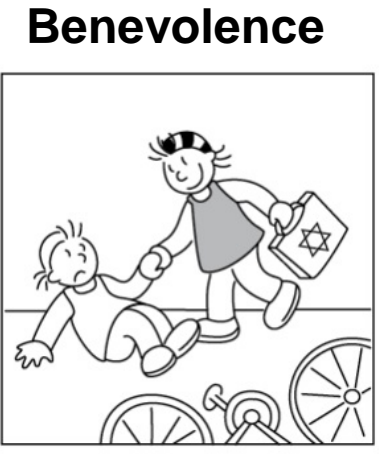

to help others

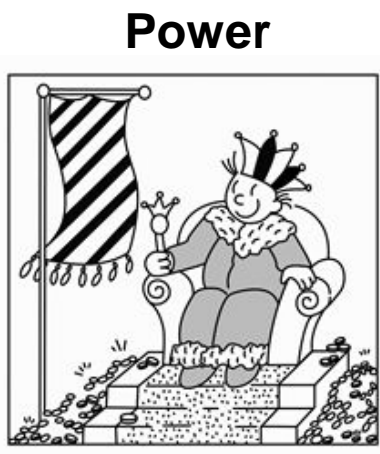

to be rich and powerful

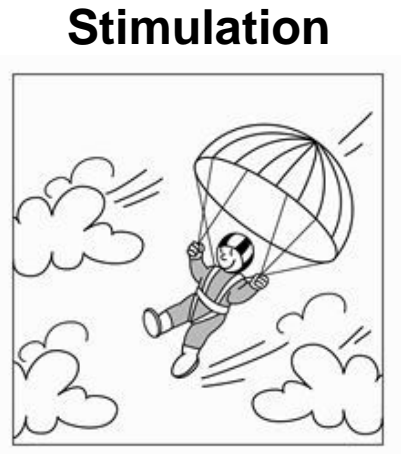

to do exciting things

\section{Conformity}

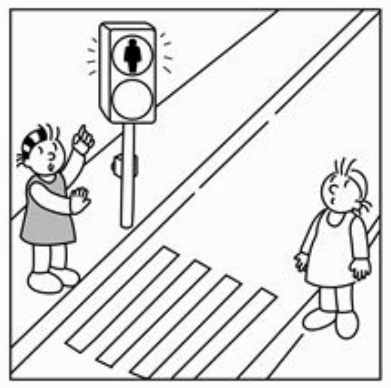

to observe the rules

Figure 2. Exemplary items (pictures and labels) of the PBVS-C. Note: Value labels do not appear with the cartoons in the original measure and are given here for convenience only. 


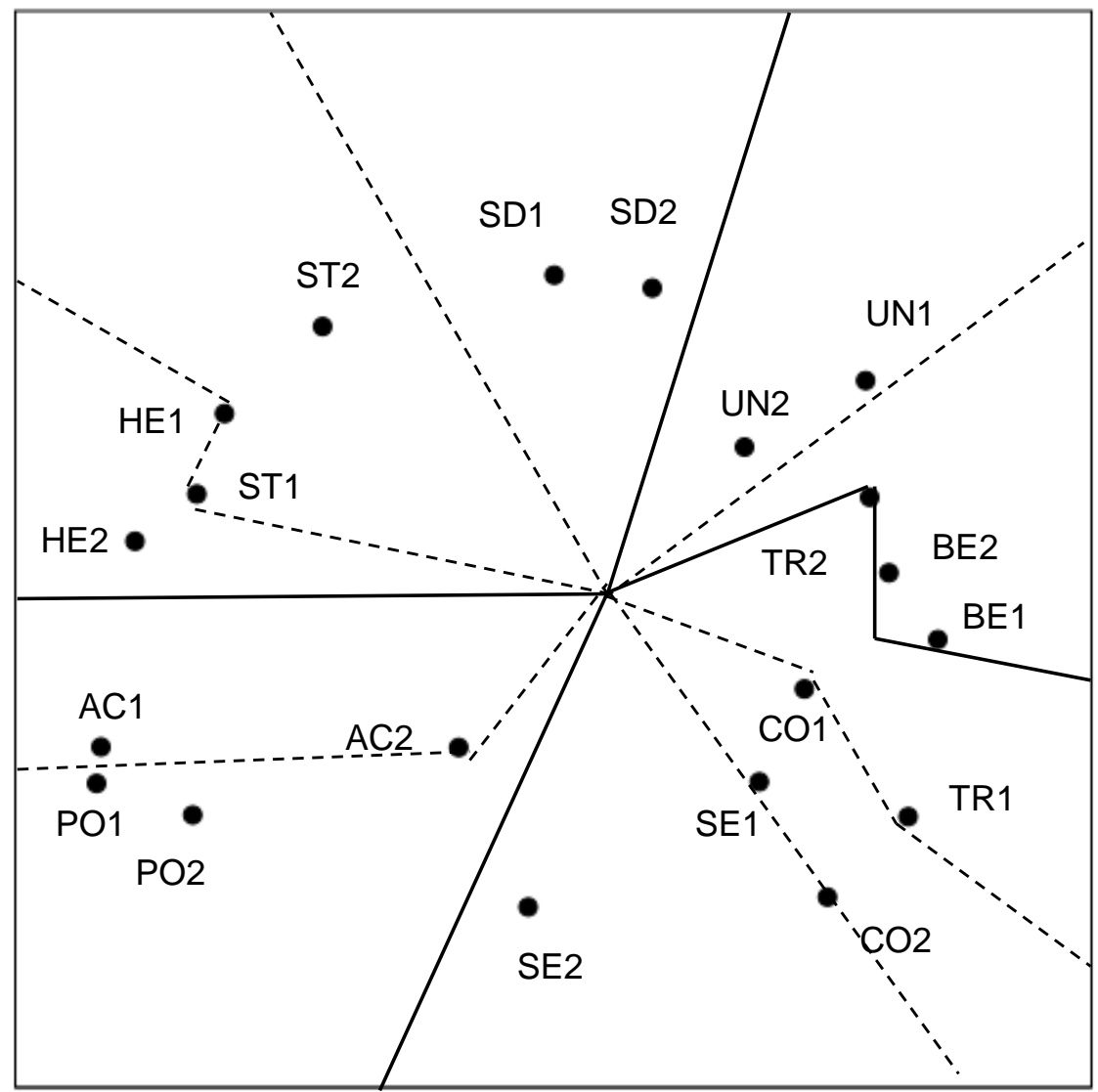

Figure 3. Multidimensional Scaling showing the structure of the PBVS-C items (each value was measured by two items). Stress $1=0.208$. UN $=$ Universalism, $\mathrm{BE}=$ Benevolence, $\mathrm{TR}=$ Tradition, $\mathrm{CO}=$ Conformity, $\mathrm{SE}=$ Security, $\mathrm{PO}=$ Power, $\mathrm{AC}=$ Achievement, $\mathrm{HE}=$ Hedonism, $\mathrm{ST}=$ Stimulation, $\mathrm{SD}=$ Self-Direction. 